\title{
Akaike criteria and selection of physiological multi-character indexes for the production of black oat seeds
}

\author{
Natã Balssan Moura ${ }^{1}$, Ivan Ricardo Carvalho ${ }^{1 *}$, José Antonio Gonzalez da Silva ${ }^{1}$, Murilo Vieira Loro ${ }^{1}$, \\ Maurício Horbach Barbosa ${ }^{2}$, Francine Lautenchleger ${ }^{3}$, Volmir Sergio Marchioro ${ }^{4}$ and Velci Queiróz de \\ Souza ${ }^{5}$
}

${ }^{1}$ Northwestern Regional University of the State of Rio Grande do Sul, ljuí, RS, Brazil. ${ }^{2}$ Tropical Genetic Improvement, Rondonópolis, MT, Brazil. ${ }^{3}$ University of the Midwest (Unicentro), Guarapuava, PR, Brazil. ${ }^{4}$ Federal University of Santa Maria, Frederico Westphalen, RS, Brazil. ${ }^{5}$ Federal University of Pampa, São Gabriel, RS, Brazil. Correspondence to: carvalho.irc@gmail.com

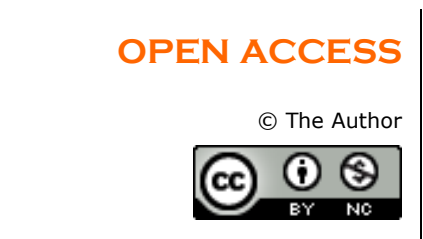

Submitted on September 15, 2020 Accepted on April 29, 2021 Early View on May 06, 2021 Final Publication on May 07, 2021

Author declares no conflict of interest

KEYWORDS: Avena strigosa Selection index Seed production

\section{ABSTRACT}

The selection of characters provides the identification of complex characteristics, the objective of the work was to use the Akaike criteria and multiple regressions to prove the multi character selection and the interrelationships based on the Phenotypic, Standardized, Willians, Multiplicative, Mulamba and Mock indexes for the selection of black oat genotypes with high physiological potential of seeds. The study was conducted in Fortaleza dos Valos RS in an experimental design used in randomized blocks with three replications. The trends for the selection of various Step Wise variables and the Akaike criteria are similar for most selection indices. For selection indexes, the phenotypic index and the standardized index correlate with the morphological characteristics, being mainly for the number of tillers. The genetic and multiplicative indices correlate with the characteristics of the seed. The phenotypic selection index was the one that stood out the most, regardless of the criterion used. This index correlates positively with the number of tillers. To select plants that present superior quality seeds, individuals with characteristics such as smaller panicles and with less spikelet ramifications and less panicle mass are sought.

\section{Highlighted Conclusions}

1. The phenotypic selection index was the one that stood out the most.

2. To obtain quality seeds, plants with smaller panicles, less spiky branching and less panicle mass are sought.

\section{INTRODUCTION}

Black oats (Avena strigosa) is a crop widely used in comparison to other winter cereals, it stands out mainly for its rusticity and low demand on soil fertility. It can be used as a cover to reduce the incidence of invasive plants, erosion, contributing to the improvement of the physical and chemical quality of the soil, when added in crop rotation systems, making it a good economic alternative in winter crops, animal feed as pasture, combined with its low production cost (Nirmalakumari et al. 2013).

For the winter crop of 2020, the area sown with black oats for the state of Rio Grande do Sul (RS) was 248,566 $\mathrm{ha}^{-1}$ (Emater 2020). Some aspects are important for the crop to present a good seed productivity, these being, based on the number of fertile tillers per unit area, number of seeds per panicle and seed mass, are considered the direct components of productivity, also considering germination and seed vigor (Hawerroth et al. 2014).

Due to the little information related to the genetic improvement of black oats, for the development of new genotypes, and biometric strategies that facilitate the selection process (Silveira et al. 2010), the use of multicharacter selection tools provides the identification of complex characteristics, being able to consider components the selection of characters of the components of yield of the oats, that present indirect improvement in the indicators of physiological quality of the seeds. These methods allow for more homogeneity, minimal losses, assignment of multiple selection strategies and rapid gains during breeding and seed production (Pelegrin et al. 2017; Sponchiado 2018; Szareski et al. 2018; Carvalho et al. 2019; Szareski et al. 2019; Corazza et al. 2020). 
In addition to developing the application of indexes, it is necessary to understand the associations and linear trends between the analyzed characteristics that may or may not be included in the multifunctional approach, allowing the breeder to identify which correlations may result in genetic gain and less time and resource expenditure during selection strategies and methods.

Due to the lack of information directed to the productive chain of black oat seeds with high physiological potential, this work aimed to employ the Akaike criteria and multiple regressions to prove the multi-character selection and the interrelationships based on the phenotypic criteria, Standardized, Willians, Multiplicative, Mulamba and Mock indices for the selection of black oat genotypes with high physiological potential of the seeds.

\section{MATERIAL AND METHODS}

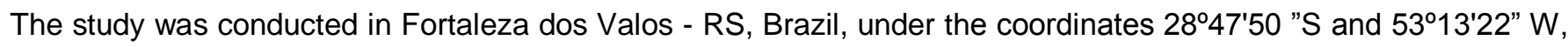
with 406 meters of altitude, corresponding to the 2019 crop season, the soil of the place is classified as dark red Latosol (Oxisol). Fourteen elite black oat genotypes were evaluated, with the physiological parameters of the seed based on the rules of the Rules for Seed Testing (Brasil 2009).

The experimental design used was a randomized block with three replications, totaling 42 experimental units composed of 10 sowing lines with 5 meters in length, spaced by 0.17 meters. The sowing took place on June 17 , 2019 at a density of 300 plants per square meter, the management of fertilization was proposed according to the soil analysis and the harvest occurred when the plants showed physiological maturation, selecting 10 representative random plants per experimental unit.

The characteristics analyzed were: first count (FC, percentage), germination (G, percentage), seedling dry mass (SDM, grams), shoot length ( $\mathrm{SL}$, centimeters), radicle length ( $\mathrm{RL}$, centimeters), plant height (PH, centimeters), panicle insertion height ( $\mathrm{IH}$, centimeters), flag leaf angle (LE, degrees), stem diameter (SD, millimeters), tiller diameter (TD, millimeters), panicle length (PL, centimeters), number of ramifications of the panicle (NR, units), panicle mass (PM, grams), number of seeds per panicle (NS, units), seed mass per panicle (SM, grams), seed length (SEL, millimeters) and seed width (SW, millimeters).

With the information obtained, different selection indexes were used in order to improve the characteristics of the genotypes, targeting the physiological aspects. The phenotypic index or classic selection index was developed by Smith (1936) and Hazel (1943), which is based on the linear combination of phenotypic values of the characters with equal economic importance to maximize the correlation between the phenotypic aggregate and the selection index, considers the value of each experimental unit weighted by its sample standard deviation of the character, the phenotypic index is calculated from the formula:

$$
P I=\left[\left(\left(\frac{f c i j}{\sigma F C i j}\right) \times\left(\frac{G i j}{\sigma G i j}\right) \times\left(\frac{S D M i j}{\sigma S D M i j}\right) \times\left(\frac{S L i j}{\sigma S L i j}\right) \times\left(\frac{R L i j}{\sigma R L i j}\right)\right)\right]
$$

where:

PI: Phenotypic multi-character index.

$F C i j$ : Values referring to the first germination count in the i-th experimental unit in the $\mathrm{j}$-th repetition.

$\sigma F C i j$ : Sample standard deviation for the first germination count.

Gij: Values referring to the germination percentage in the i-th experimental unit in the j-th repetition.

$\sigma G i j$ : Sample standard deviation for germination percentage.

$S D M i j$ : Values referring to seedling dry mass in the i-th experimental unit in the $j$-th repetition.

GSDMij: Sample standard deviation for seedling dry mass.

$S L i j$ : Values referring to the shoot length of the seedling in the $\mathrm{i}$-th experimental unit in the j-th repetition.

$\sigma S L i j$ : Sample standard deviation for the shoot length of the seedling

$R L i j$ : Values regarding the seedling root length in the $\mathrm{i}$-th experimental unit in the j-th repetition

$\sigma R L i j$ : Sample standard deviation for seedling root length.

The standardized selection index is obtained through the phenotypic effects standardized by subtracting the arithmetic mean and weighted by the effects of the sample standard deviations (Gesteira et al. 2018), according to the formula:

$$
Z I=\left[\left(\left(\frac{F C i j-\bar{\gamma} F C i j}{\sigma F C i j}\right)+\left(\frac{G i j-\bar{\gamma} G i j}{\sigma G i j}\right)+\left(\frac{S D M i j-\bar{\gamma} S D M i j}{\sigma S D M i j}\right)+\left(\frac{S L i j-\bar{\gamma} S L i j}{\sigma S L i j}\right)+\left(\frac{R L i j-\bar{\gamma} R L i j}{\sigma R L i j}\right)\right)\right]
$$


where:

ZI: Standardized Multicharacter Selection Index

FCij: Values referring to the first germination count in the i-th experimental unit in the j-th repetition.

$\bar{\gamma} F C i j$ : General average for first germination count in the $\mathrm{i}$-th experimental unit in the $j$-th repetition.

$\sigma F C i j$ : Standard deviation for first germination count in the $\mathrm{i}$-th experimental unit in the j-th repetition.

PGij: Values referring to the germination percentage in the $\mathrm{i}$-th experimental unit in the j-th repetition.

$\bar{\gamma} G i j$ : General average for the germination percentage in the i-th experimental unit in the j-th repetition.

$\sigma$ Gij: Standard deviation for the germination percentage in the i-th experimental unit in the j-th repetition.

$S D M i j$ : Values referring to seedling dry mass in the i-th experimental unit in the j-th repetition

$\bar{\gamma} S D M i j$ : General average of the seedling dry mass in the i-th experimental unit in the $j$-th repetition.

бSDM ij: Standard deviation for seedling dry mass in the i-th experimental unit in the j-th repetition.

$S L i j$ : Values referring to the seedling shoot length in the i-th experimental unit in the j-th repetition.

$\bar{\gamma} S L i j$ : General average for the seedling shoot length in the i-th experimental unit in the j-th repetition.

$\sigma S L i j$ : Standard deviation for the seedling shoot length in the $\mathrm{i}$-th experimental unit in the j-th repetition

$R L i j$ : Values referring to seedling root length in the $\mathrm{i}$-th experimental unit in the j-th repetition.

$\bar{\gamma} R L i j$ : General average for seedling root length in the i-th experimental unit in the j-th repetition.

$\sigma R L i j$ : Standard deviation for seedling root length in the $\mathrm{i}$-th experimental unit in the j-th repetition.

The Willians index consists of the product between the economic weight of the character and the phenotypic value that will be compiled in a producer (Sponchiado 2018). The weight of each character was determined as follows: percentage of germination $(50 \%)$, seedling dry mass $(20 \%)$, seedling shoot length $(12.5 \%)$, radicle length $(12.5 \%)$ and first germination count (5\%), according to the formula:

$W I=[((P 1 \% \times \bar{\gamma} F C i j)+(P 2 \% \times \bar{\gamma} G i j)+(P 3 \% \times \bar{\gamma} S D M i j)+(P 4 \% \times \bar{\gamma} S L i j)+(P 5 \% \times \bar{\gamma} R L i j))]$ where:

Wl: Willians Index.

$P 1 \%$ : Economic weight attributed to the variable.

$\bar{\gamma} F C i$ : Phenotypic mean of the genotype for the first germination count in the i-th experimental unit in the j-th repetition.

$P 2 \%$ : Economic weight attributed to the variable

$\bar{\gamma} G i$ : Phenotypic mean of the genotype for the germination percentage in the i-th experimental unit in the j-th repetition

$P 3 \%$ : Economic weight attributed to the variable

$\bar{\gamma} S D M i$ : Phenotypic mean of the genotype for the dry mass in the i-th experimental unit in the j-th repetition.

$P 4 \%$ : Economic weight attributed to each variable

$\bar{\gamma} S L i$ : Phenotypic mean of the genotype for the shoot length in the i-th experimental unit in the j-th repetition,

$P 5 \%$ : Economic weight attributed to each variable.

$\bar{\gamma} R L i$ : Phenotypic mean of the genotype for root length in the i-th experimental unit in the $\mathrm{j}$-th repetition.

The multiplicative index was obtained by the producer of the predicted genetic values of each specific genotype per experimental unit, these estimates being obtained by the restricted maximum likelihood (REML) and the predictions extracted by the Best unbiased prediction (BLUP) (Silva et al. 2017), the multiplicative index was calculated using the formula:

\section{$M I=[(V g F C i j \times V g$ Gij $\times V g S D M i j \times V g S L i j \times V g R L i j)]$}

where:

MI: Multiplicative Index.

VgFCij: Genetic value for the first germination count in the i-th experimental unit in the j-th repetition.

VgGij: Genetic value for the germination percentage in the i-th experimental unit in the j-th repetition.

VgSDMij: Genetic value for seedling dry mass in the i-th experimental unit in the j-th repetition.

VgSLij: Genetic value for seedling shoot length in the i-th experimental unit in the j-th repetition.

VgRLij: Genetic value for seedling root length in the i-th experimental unit in the j-th repetition. 
The Mulamba and Mock index is based on the sum of the predietive genetic ranks obtained by REML and BLUP for each genotype multiplied by (economic weights (percentage of germination (50\%), seedling dry mass $(20 \%)$, seedling shoot length (12.5\%), root length (12.5\%) and first germination count (5\%) (Bizari et al., 2017), according to the formula:

$M M I=[(P 1 \%$ FCij $+P 2 \% G i j+P 3 \% S D M i j+P 4 \% S L i j+P 5 \% R L i j)]$

where:

MMI: Mulamba and Mock Index

$P 1 \%$ : Economic weight attributed to the variable

FCij: Value for the first germination count in the i-th experimental unit in the $j$-th repetition.

$P 2 \%$ : Economic weight attributed to the variable

Gij: Value for the germination percentage in the i-th experimental unit in the j-th repetition.

$P 3 \%$ : Economic weight attributed to the variable.

$S D M i j$ : Value for seedling dry mass in the i-th experimental unit in the $\mathrm{j}$-th repetition.

$P 4 \%$ : Economic weight attributed to each variable

$S L i j$ : Value for the seedling shoot length in the i-th experimental unit in the j-th repetition.

P5\%: Economic weight attributed to each variable.

$R L i j$ : Value for the seedling root length in the $\mathrm{i}$-th experimental unit in the $\mathrm{j}$-th repetition.

The data were submitted to the assumptions, normality and homogeneity of the residual variances and additivity of the statistical model. Afterwards, analysis of variance at $5 \%$ probability was used to identify the attribution to the effects of the different genotypes. To identify the trend of association between the characters, linear correlation was applied to all variables and indices with significance based on the test at $5 \%$ probability, as the main character was attributed to the selection indices, and the methods of multiple regression with the Stepwise algorithm and the selection of models by the Akaike criterion to identify the independent variables determining the indices and their respective contributions. Due to the various characters involved, multivariate tools were applied, such as canonical correlations to define the interrelations between group I (selection indexes) and the other measured components. Subsequently, the Mahalanobis algorithm was applied to obtain the matrix of distances weighted by the residual matrix that served as the basis for the Unweighted Pair Group Method with Arithmatic Mean (UPGMA) grouping.

\section{RESULTS AND DISCUSSION}

The predictor models presented similar trends for the multi-character indexes, both by the multiple regression methodology with selection of variables by Step Wise and by the Akaike criteria (Table 1). The use of the Stepwise multiple regression method, used mainly to select the variables that most influence the output set, in this way can decrease the number of variables that make up the regression equation (Alves et al. 2013). One of the most used selection criteria is the linear regression of the $F$ test, which is used since it has a normal distribution (Silva Junior et al. 2017). The indexes of selection of variables by multiple Step Wise regression showed similarity between the phenotypic index (IF) and the multiplicative index (IM), since they consider the multiplication of the results between the variables. The first index considers the values obtained from the count of each variable divided by the standard deviation and the second considers the genetic value of each variable multiplied with each other.

Table 1. Predictive models based on multiple Step Wise regression and Akaike criteria.

\begin{tabular}{|c|c|c|c|c|c|c|}
\hline \multicolumn{7}{|c|}{ Predictive model } \\
\hline Multicharacter Index & \multicolumn{6}{|c|}{ Based on Multiple Regression (Step Wise) } \\
\hline $\mathrm{Y}$ & Intercept & FC & $\mathrm{G}$ & SDM & SL & $\mathrm{RL}$ \\
\hline $\mathrm{Pl}^{*}$ & -318833 & 509.45396 & 1412.48547 & 1322541 & 7757.86989 & 8179.13355 \\
\hline ZI & -32.50681 & 0.09624 & 0.08976 & 105.54398 & 0.73122 & 0.2979 \\
\hline WI & 0.00111 & 5.00001 & 49.99999 & 19.97791 & 12.50003 & 12.5000 \\
\hline MI & -49754 & 222.51077 & 534.45155 & 129183 & 1559.87122 & 562.15814 \\
\hline \multirow[t]{2}{*}{ MMI } & 121.01036 & - & -0.64744 & -327.72848 & - & -101175 \\
\hline & \multicolumn{6}{|c|}{ Based on the Akaike Criteria } \\
\hline $\mathrm{PI}$ & -318800 & 7758 & 8179 & 1412.0 & 1323000 & 509.5 \\
\hline ZI & $-3.251^{01}$ & 0.7309 & 0.2979 & 0.08987 & 105.6 & 0.09613 \\
\hline WI & $5.122^{-12}$ & 12.500 & 12.50 & 50.00 & 20.0 & 5.000 \\
\hline MI & -49750 & 1560.0 & 562.2 & 534.5 & 120200.0 & 222.5 \\
\hline MMI & 121.00 & - & -1.0120 & -0.6474 & - & -327.70 \\
\hline
\end{tabular}


For the Akaike criterion it is estimated by using the formula AIC $=-2 \log L+2 p$, where $p$ is $p$ number of estimated parameters, so the lower the index values, it refers to a better fit of the model (Resende et al. 2014). According to the same author, this criterion penalizes verisimilitude by the number of adjusted independent parameters, the lowest values show a better global adjustment, that is, it shows the best model. This methodology can be used to compare any type of model: linear, non-linear, nested and non-nested (Floriano et al. 2006). The indices that are similar for the first count variable were the classic Willians index (IW) and the multiplicative index (IM). The first index considers the evaluation of the economic weights of each variable, multiplied by the average of each variable, and the second index considers the genetic value of each variable multiplied with each other. For the variable length of aerial part, similar indices were the phenotypic index (IF) and the multiplicative index (IM). For most indexes, the selection criteria show positive trends. The Mulamba and Mock index is the one that presents the greatest difference from the others, due to the fact that they consider the ranking of each variable.

The Akaike criteria show that the indexes express variables with a positive effect, in contrast to the Mulamba and Mock index (MMI), which has an opposite effect to the other indexes. The highlight variable for this index was germination percentage $(\mathrm{G})$. For the phenotypic index $(\mathrm{PI})$, the variable that presented the greatest magnitude was the seedling shoot length (SL). For the Standardized Selection Index (ZI) the best answers were found for the variables seedling root length $(\mathrm{RL})$ and seedling dry mass (SDM). For the Willians index (WI) the variables that stood out were the first germination count ( $F C$ ) and radicle length ( $R L)$. Analyzing the multiplicative index (MI), the response variable that stood out positively was the seedling shoot length (SL).

The linear correlations (Figure 1) between the components of the panicle and the phenotypic indices, for the selection aiming at increasing the Number of Tillers (NT), the indices that contribute to the increase of the expression of this characteristic are the Phenotypic Index (PI) and the Willians Index (WI). For the height increase of $(\mathrm{PH})$, the characteristics that tend to increase are the panicle insertion height $(\mathrm{IH})$ and the flag leaf angulation (LE). The same occurs for the increase in IH, as there is an increase in LE, since they are related morphological characteristics. For the characteristic tiller diameter (TD), the index that presents the greatest contribution to the expression of this characteristic is the Ml.

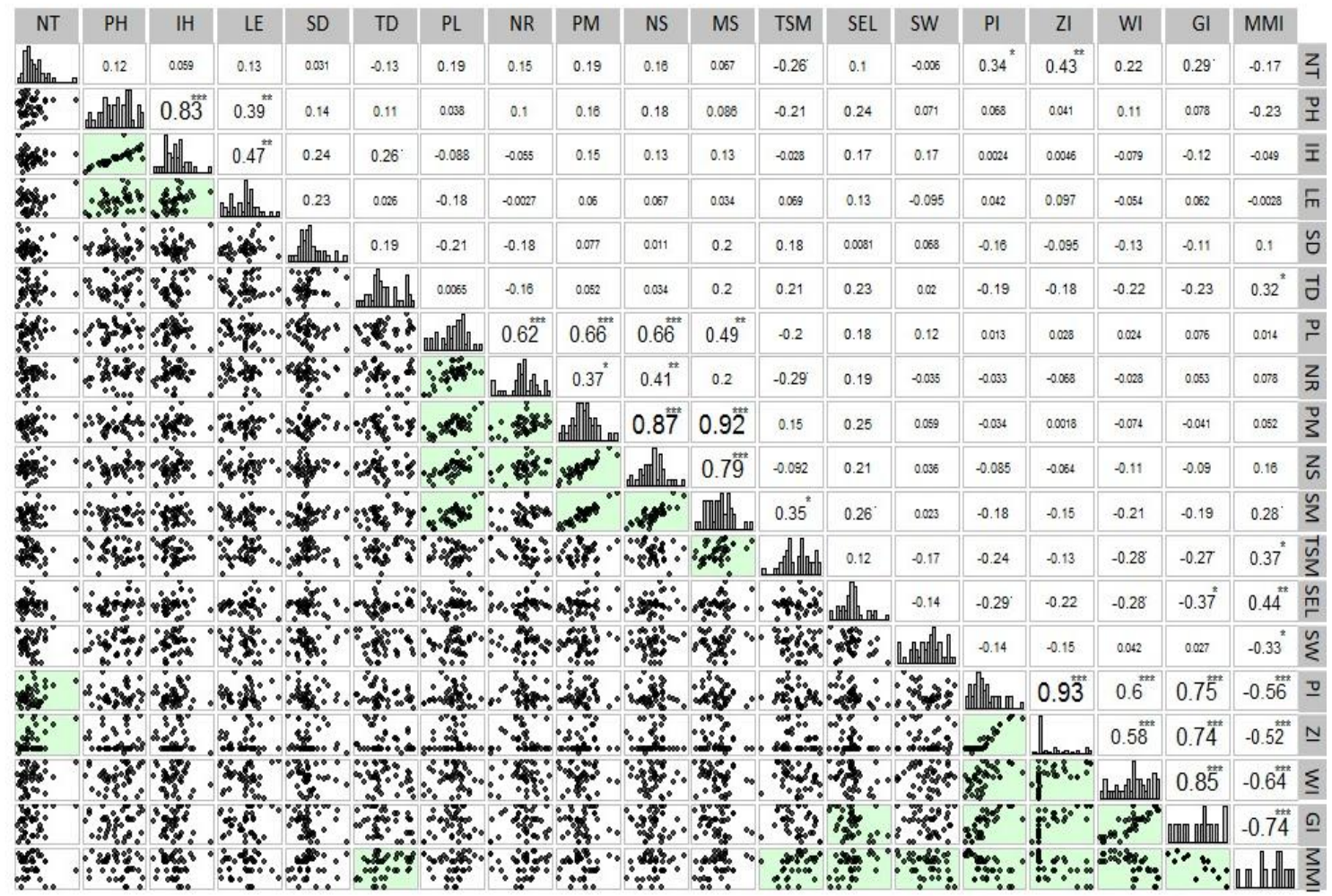

Figure 1. Estimates of Pearson's linear correlation for seed quality, agronomic characteristics and multicharacter indexes for black oats.

* Pearson's linear correlation coefficients, significant at $5 \%$ probability of error. NT: Number of tillers; PH: Plant height; IH: Panicle insertion height; LE: Flag leaf angulation; SD: Stem diameter; TD: Tiller diameter; PL: Panicle length; NR: Number of ramificationa; PM: Panicle mass; NS: Number of Seeds; SM: Seed Mass; TSM: thousand seed mass; SEL: Seed Length; SW: Seed Width; PI: Phenotypic Index; ZI: Standardized Selection Index; WI: Classic William Index; MI: Multiplicative Index; MMI: Mulamba and Mock Index. 
For the panicle length $(\mathrm{PL})$ at the moment it seeks to increase it, there is an increase in the number of ramifications (NR), panicle mass (PM), number of seeds (NS) and seed mass (SM). According to studies by Meira et al. (2017) reports that the size and weight of seeds are related to vigor and seedling germination. Thus, it can be said that larger panicles tend to have a higher grain yield. To increase the number of ramifications (NR), there is an increase in panicle mass (PM) and number of seeds (NS), that is, more branched panicles tend to have a number of seeds and panicle mass, and with the increase of panicle mass (PM), there is an increase in the number of seeds (NS) and seed mass (SM). With the increase in the number of seeds (NS), there is an increase in the seed mass (SM). Studies by Meira et al. (2019a), report that the increase in productivity is highly correlated with the increase in the number of grains per plant and grain weight. By increasing the seed mass (SM), there are increases in TSM.

For the TSM variable, the index that contributes to the expression of this characteristic is the MI. For SEL, the indexes that best present this characteristic are GI and MI, and for SW the index that contributes to its expression is Ml. Therefore, one must choose these indexes to carry out the indirect selection for this characteristic. Linear correlation helps as a tool that helps to demonstrate which characteristics increase a given variable.

The canonical correlations were stratified into two distinct groups of characteristics, group 1 is related to the selection indexes of the maximum physiological potential of oat seed and group 2 considers the morphological components of oat panicle, namely: Panicle length (PL), Number of ramifications (NR), Panicle Mass (PM). And physical characteristics of the seed, which are: Number of Seeds (NS), Seed Mass (SM), Seed Length (SEL) and Seed Width (SW). There was significance for the maximum likelihood between the groups of characters, stating that there is a linear dependence between these characteristics, confirmed by the high interclass correlation of 0.85 (Table 2).

Table 2. Estimates of correlations between selection indexes (group 1) and morphological characters (group 2) in black oat genotypes.

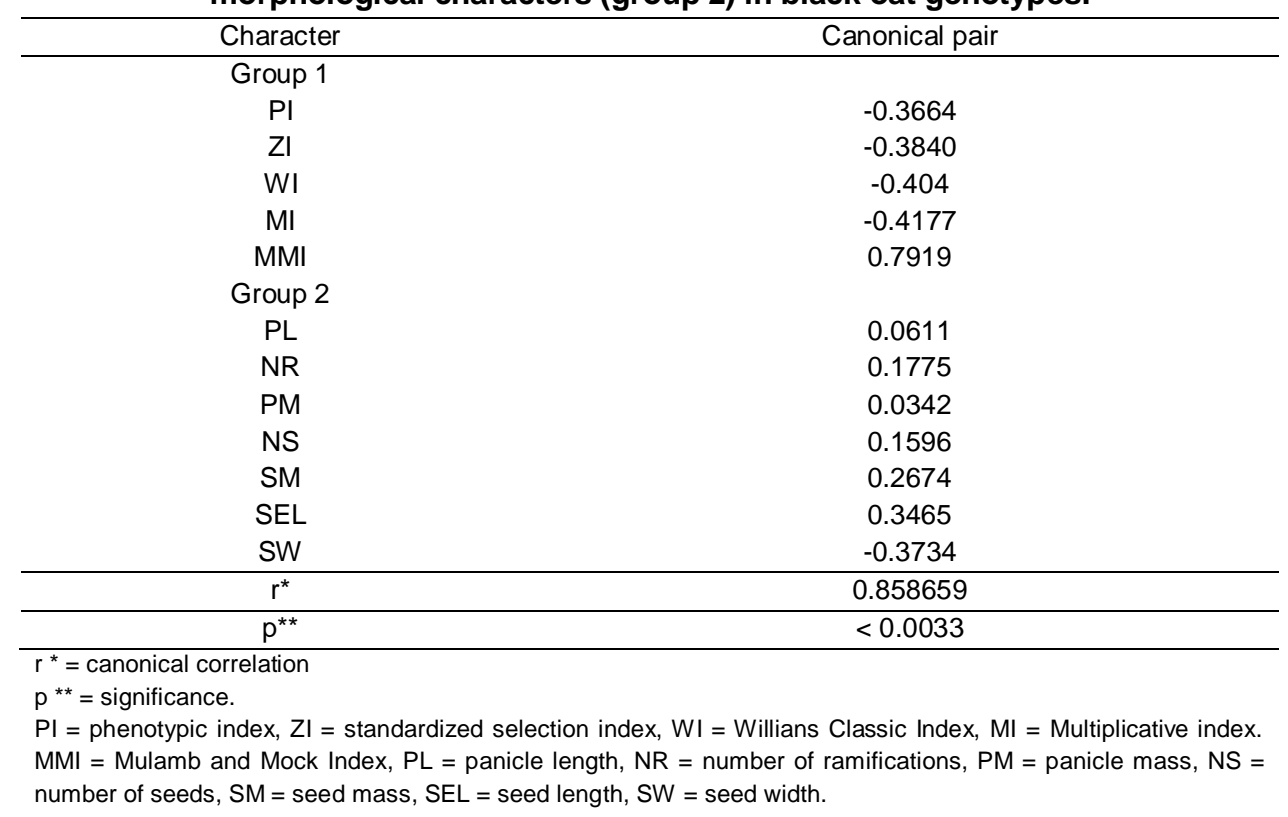

It was then sought to evidence which characteristics relevant to group 2 that determine group 1 , focus of selection in the indirect field, it was based then that the canonical loads of the characteristics of group 2 positively influence for: PL, NR, PM, NS, SM, SEL and negative for SW. For group 1, the canonical characteristics positively influenced the MI index, and negatively the PI, ZI, WI, MI. For this purpose, from a biological point of view, the focus of indirect selection is to increase the physiological potential of seed in the field based on multicharacteristic indices. Among the indices that stand out in the same direction, were the $\mathrm{PI}, \mathrm{ZI}, \mathrm{WI}, \mathrm{MI}$ which sought to select plants that express smaller panicle lengths, followed by fewer spikelet branches per panicle and less panicle mass because they are morphological characteristics, such as a drain of photoassimilates and partition of assimilates to the plant. In this way, these characteristics will reduce the number and mass of panicle seeds followed by their length, however this will increase the width of the seed. With this parameter, it is possible to identify that from the width of the seed, it is possible to focus on the indirect selection in two ways, one based on the dimensions of the panicle and the other based on the dimensions of the seed, an agronomic ideotype for seed production. with greater vigor, they would be larger, shorter seeds, formed in smaller panicles, with less seeds and fewer branches, so that the objective of selection in an breeding program was achieved. 
For $\mathrm{MMI}$, it presents the following relation for indirect selection, where the characteristics that stand out are plants with greater panicle length, greater number of panicle branches, greater panicle mass, greater number of seeds, greater seed mass, greater length of the seed and shorter seed width. Selection based on panicle length, panicle weight, number of panicle grains and grain weight can result in greater selection gain, due to heritability values greater than $80 \%$ for these characters (Meira et al. 2019b, 2019c).

The dendrogram (Figure 2) shows that the studied genotypes have similarity for two large groups, with the group in blue standing out for a greater number of genotypes with similar characteristics.

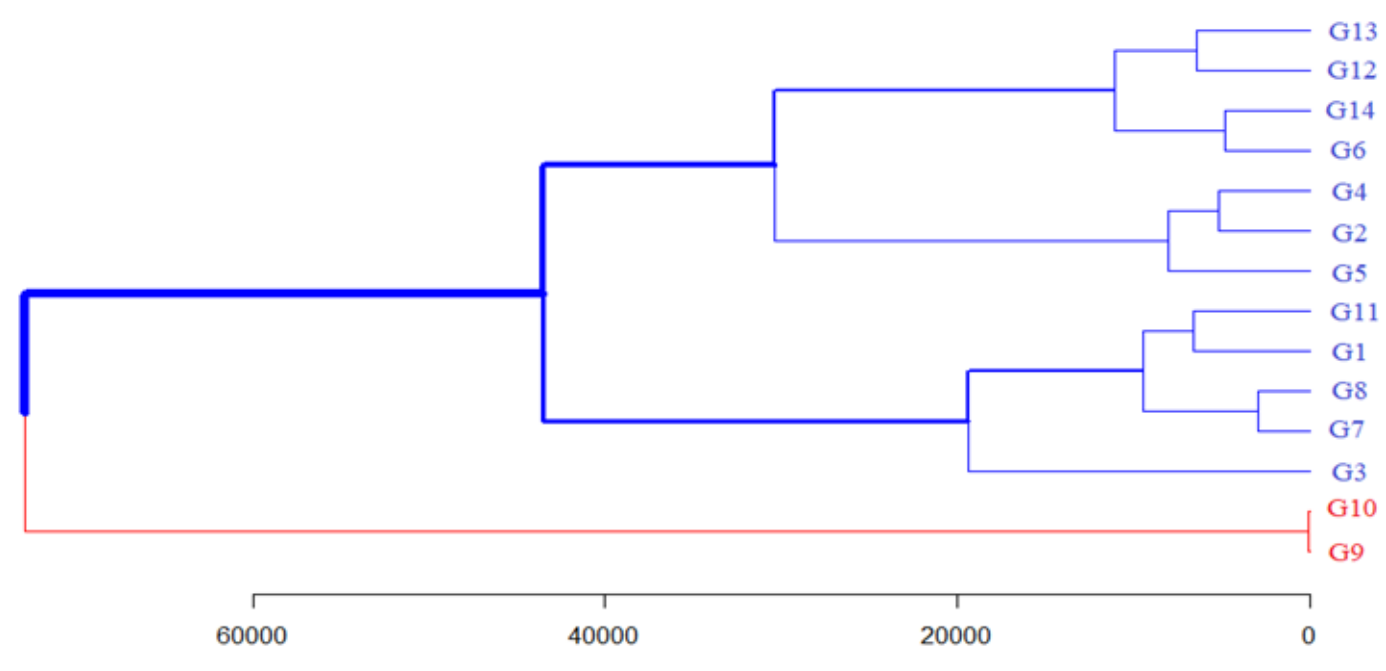

Genetic Distance

Figure 2. Dissimilarity expressed by the dendrogram obtained by the Mahalanobis algorithm and the method of medium connections (UPGMA), based on the information of the characters first count (FC, percentage), germination (G, percentage), seedling dry mass (SDM, grams), shoot length (SL, centimeters), radicle length (RL, centimeters), plant height (PH, centimeters), panicle insertion height (IH, centimeters), flag leaf angle (LE, degrees), stem diameter (SD, millimeters), tiller diameter (TD, millimeters), panicle length (PL, centimeters), number of ramifications (NR, units), panicle mass (PM, grams), number of seeds per panicle (NS, units), seed mass per panicle (SM, grams), seed length (SEL, millimeters) and seed width (SW, millimeters).

The trends for the selection of multiple Step Wise variables and the Akaike criteria are similar for most selection indexes. The Phenotypic Index (PI) and the Multiplicative Index (MI), were similar for the multiple selection of Step Wise and for the Akaike criteria the indices that were similar were the Classic Willians Index (WI) and the Multiplicative Index (MI), for the variable first count and the phenotypic index (PI) and multiplicative (MI) for the variable shoot. For selection indexes, the phenotypic index (PI) and the standardized index (ZI) correlate with morphological characteristics, being mainly for the number of tillers. The GI and the multiplicative (MI) indices correlate mainly with seed characteristics, such as width, length. Similar indices, based on the multiple selection of Step wise, are the phenotypic index and the multiplicative index, for the Akaike criteria, the indices that show similarity were the classic Willians index and the multiplicative index for the first count and the phenotypic index and the multiplicative for the shoot length.

\section{References}

Alves MF et al. 2013. Seleção de variáveis stepwise aplicadas em redes neurais artificiais para previsão de demanda de cargas elétricas. Proceeding Series of the Brazilian Society of Computational and Applied Mathematics 1:e0144.

Brasil. 2009. Ministério da Agricultura, Pecuária e Abastecimento. Regras para Análise de Sementes. Ministério da Agricultura, Pecuária e Abastecimento. Secretaria de Defesa Agropecuária. Brasília, DF: Mapa/ACS. 398p.

Bizari EH et al. 2017. Índices de seleção para caracteres agronômicos em populações segregantes de soja. Revista Ciência Agronômica 48:110-117.

Corazza T et al. 2020. Mixed model and multivariate approaches are useful tools for breeding of bifortfied and bioactive compound in maize. Australian Journal of Crop Science 14:1-8.

Carvalho IR et al. 2019. Phenotypic multicarter selection approach to predict genetics applied in the segregating generations F2, F3 and F4 of common black beans. Plant Omics Journal 12:25-30.

Emater. 2020. Acompanhamento de Safras 2020. http://www.emater.tche.br/site/arquivos_pdf/safra/safraTabela_18062020.pdf.

Floriano EP et al. 2016. Ajuste e seleção de modelos tradicionais para série temporal de dados de altura de árvores. Ciência Florestal 16:177199. 
Gesteira GDS et al. 2018. Selection of early soybean inbred lines using multiple indices. Embrapa Soja-Artigo em periódico indexado (ALICE). https://www.embrapa.br/busca-de-publicacoes/-/publicacao/1105536/selection-of-early-soybean-inbred-lines-using-multiple-indices.

Hazel LN. 1943. The genetic basis for constructing selection indexes. Genetics 28:476-490.

Nirmalakumari A et al. 2013. Trait association and path analysis for grain yield in oat in the western zone of Tamil Nadu. International Journal of Agricultural Science and Research 3:309-316.

Meira D et al. 2017. Physiological traits and their relationships in black oat populations. Genetics and Molecular Research 16:gmr16039814.

Meira D et al. 2019a. Multivariate analysis revealed genetic divergence and promising traits for indirect selection in black oat. Revista Brasileira de Ciências Agrárias 14:e6514.

Meira D et al. 2019b. Estimates of genetic parameters between and within black oat populations. Bragantia 78:43-51.

Meira D et al. 2019c. Phenotypic variance of black oat growing in crop seasons reveals genetic effects predominance. Anais da Academia Brasileira de Ciências 91:e20180036

Hawerroth MC et al. 2014. Importância e dinâmica de caracteres na aveia produtora de grãos. Embrapa Documentos $376,56$. http://ainfo.cnptia.embrapa.br/digital/bitstream/item/115981/1/documento376-web.pdf

Pelegrin AJ et al. 2017. Adaptability, Stability and Multivariate Selection by Mixed Models. American Journal of Plant Sciences 8:3324-3337.

Resende MDV et al. 2014. Estatística matemática, biométrica e computacional - Suprema, Viçosa - MG.

Silva VB et al. 2017. Prediction of genetic gains by selection indices using mixed models in elephant grass for energy purposes. Embrapa Milho e Sorgo 16:gmr16039781

Silva EGJ. 2017. Seleção de genótipos de algodoeiro utilizando redes neurais artificiais. Trabalho de Conclusão de Curso (Graduação em Agronomia) - Universidade Federal de Uberlândia, Uberlândia. http://repositorio.ufu.br/handle/123456789/18053.

Silveira $\mathrm{G}$ et al. 2010. Variabilidade genética para características agronômicas superiores em cruzamentos biparentais de aveia preta. Bragantia 69:823-832.

Smith F. 1936. A discriminant function for plant selection. Annals of Eugenics 7:240-250.

Sponchiado S. 2018. Uso de REML/BLUP na seleção de genitores para a obtenção de híbridos produtivos e precoces de sorgo granífero. Thesis (Master in Genetics and Breeding) - Universidade do Estado de Matogrosso. http://portal.unemat.br/media/files/Dissertacao_Sandro\%20Sponchiado.pdf.

Szareski VJ et al. 2018. Multivariate index of soybean seed vigor: a new biometric approach applied to the effects of genotypes and environments. Journal of Seed Sciences 40:396-406.

Szareski VJ et al. 2019. Genetic and phenotypic multi-character approach applied to multivariate models for wheat industrial quality analysis. Genetics and Molecular Research 18:gmr18223. 